Article

\title{
The Difference of Lamellar Structure Formation between Ti-45Al-5.4V-3.6Nb-Y Alloy and Ti-44Al-4Nb-4V-0.3Mo-Y Alloy
}

\author{
Jianchao Han ${ }^{1}$, Shuzhi Zhang ${ }^{2,3} \mathbb{D}$, Changjiang Zhang ${ }^{2}$, Fantao Kong ${ }^{4}$, Yuyong Chen 4 (D) and \\ Fei Yang ${ }^{3, *(1)}$ \\ 1 College of Mechanical Engineering, Taiyuan University of Technology, Taiyuan 030024, China; \\ hanjianchao@tyut.edu.cn \\ 2 School of Materials Science and Engineering, Taiyuan University of Technology, Taiyuan 030024, China; \\ zhshzh1984@163.com (S.Z.); zhangchangjiang@tyut.edu.cn (C.Z.) \\ 3 Waikato Centre for Advanced Materials, School of Engineering, University of Waikato, Hamilton 3240, \\ New Zealand \\ 4 National Key Laboratory for Precision Hot Processing of Metals, Harbin Institute of Technology, \\ Harbin 150001, China; kft@hit.edu.cn (F.K.); yychen@hit.edu.cn (Y.C.) \\ * Correspondence: fei.yang@waikato.ac.nz or fyang0204@hotmail.com; Tel.: +64-7-837-9417
}

Received: 1 June 2018; Accepted: 3 July 2018; Published: 24 July 2018

check for updates

\begin{abstract}
In this study, the effect factors on the formation of lamellar structure for Ti-45Al$5.4 \mathrm{~V}-3.6 \mathrm{Nb}-\mathrm{Y}$ alloy and Ti-44Al-4Nb-4V-0.3Mo-Y alloy is discussed in detail. During heat treatment in different procedures, temperature was the common factor influencing the formation of lamellar structure of Ti-45Al-5.4V-3.6Nb-Y and Ti-44Al-4Nb-4V-0.3Mo-Y alloys. In the range of $1230{ }^{\circ} \mathrm{C}$ and $1300{ }^{\circ} \mathrm{C}$, the volume fraction of lamellar structure in Ti-45Al-5.4V-3.6Nb-Y alloy was proportional to the annealing temperature. However, between $1210{ }^{\circ} \mathrm{C}$ and $1260{ }^{\circ} \mathrm{C}$, the volume fraction of lamellar structure in Ti-44Al-4Nb-4V-0.3Mo-Y alloy deceased when temperature was located in the $\alpha+\gamma+\beta$ triple phase field and then increased when temperature was in the $\alpha+\beta$ binary phase field. Besides the influence of temperature, the lamellar structure formation of Ti-44Al-4Nb-4V-0.3Mo-Y alloy was also affected by the $\beta$-phase stabilizing element.
\end{abstract}

Keywords: TiAl alloys; lamellar structure; phase transformation; $\beta$ phase stabilizing element

\section{Introduction}

TiAl based alloys are attractive for use in advanced propulsion systems for aircraft and also in automobile engine parts, due to the combination of low density, high specific strength, high specific stiffness, good creep strength up to $700{ }^{\circ} \mathrm{C}$, and better high temperature oxidation resistance than titanium alloys [1-4]. However, low room temperature ductility and poor formability limit their extensive application [5,6]. During the last decades, considerable efforts have been devoted to improving their room temperature ductility and formability and some typical TiAl alloys and components have been developed by optimizing the composition and processing routes. By means of reducing $\mathrm{Al}$ content and adding $\beta$-phase stabilizing elements, $\beta$-solidifying TiAl alloy is designed to solidify via the solidification path as $\mathrm{L} \rightarrow \beta \rightarrow \alpha \ldots$ instead of the $\mathrm{L}+\beta \rightarrow \alpha$ peritectic solidification path. This kind of alloy reportedly attains adequately balanced mechanical properties via conventional manufacturing routes and heat treatments due to the enlarged processing window $[7,8]$. As a typical $\beta$-solidifying TiAl alloy, TNM alloy has been isothermally forged into blades for the engine PW1134G [9]. 
Lamellar structure is a main and essential component for TiAl based alloys, regardless of whether they are in as-cast or hot-working (hot forging, hot extrusion, or hot rolling) conditions $[2,5,10,11]$. Furthermore, lamellar structure with small grain size is currently regarded as the most attractive microstructure for a TiAl alloy, due to the excellent combination of yield strength, ductility, fracture toughness, and creep resistance $[12,13]$. It is commonly acknowledged that the lamellar structure of traditional TiAl alloy is the product of the transformation of $\alpha \rightarrow \alpha_{2}+\gamma, \alpha \rightarrow \alpha_{2} \rightarrow \alpha_{2}$ $+\gamma$ or $\alpha \rightarrow \alpha+\gamma \rightarrow \alpha_{2}+\gamma[14,15]$. However, unlike the traditional TiAl alloy which only consists of $\alpha_{2}$-phase and $\gamma$-phase at room temperature, a $\beta$-solidifying TiAl alloy is composed of $\alpha / \alpha_{2^{-}}, \beta / \beta_{0^{-}}$, and $\gamma$-phases at room temperature. The formation mechanism of lamellar structure is reasonably influenced by $\beta / \beta_{0}$-phase and $\beta$-phase stabilizing elements. Therefore, the heat treatment to obtain fully $\left(\alpha_{2}+\gamma\right)$ lamellar structure is different for the two kinds of TiAl alloy. As a $\beta$-solidifying TiAl alloy, Ti-44Al-6Nb-2Mo-Y alloy is reported to produce fully lamellar structure through short term annealing at temperatures slightly above $\beta$-transus, instead of annealing in the single $\alpha$ phase field (the typical fully lamellar treatment for peritectic solidification TiAl alloy) [16]. Thus, the formation of lamellar structure of $\beta$-solidifying TiAl alloy is complicated and affected by multiple factors. Therefore, it is essential to understand the lamellar structure formation of the $\beta$-solidifying TiAl alloy and to study the effect of $\beta / \beta_{0}$-phase on the formation of lamellar structure.

In this study, two $\beta$-solidifying TiAl alloys, Ti-45Al-5.4V-3.6Nb-Y and Ti-44Al-4Nb-4V-0.3Mo-Y alloy, were adopted. The lamellar microstructure and formation characteristics of the two alloys were studied carefully. Moreover, by comparing the formation of lamellar structure in Ti-45Al-5.4V-3.6Nb-Y and $\mathrm{Ti}-44 \mathrm{Al}-4 \mathrm{Nb}-4 \mathrm{~V}-0.3 \mathrm{Mo}-\mathrm{Y}$ alloy, the influence factors were discussed and the dominant factor was revealed.

\section{Experimental Procedure}

Ingots of Ti-44Al-4Nb-4V-0.3Mo-Y and Ti-45Al-5.4V-3.6Nb-Y alloy were fabricated by induction skull melting (ISM) technique and subsequently followed by hot isostatic pressing (HIP) at $1200{ }^{\circ} \mathrm{C}$ for $3 \mathrm{~h}$ under a pressure of $130 \mathrm{MPa}$ in argon atmosphere. Cylindrical blanks with dimensions of $\varnothing 60 \mathrm{~mm} \times 100 \mathrm{~mm}$ were cut from the Ti-45Al-5.4V-3.6Nb-Y cast ingot by electric-discharge machining and then canned in 304 stainless steel tubes with a thickness of $10 \mathrm{~mm}$. The canned blank was forged by two-step forging at $1250{ }^{\circ} \mathrm{C}$ with a strain rate of $0.05 \mathrm{~s}^{-1}$. The total reduction of the canned blank was about $80 \%$.

Heat treatment specimens with a dimension of $10 \times 10 \times 10 \mathrm{~mm}^{3}$ were cut using an electrical-discharge method from the ingots of Ti-44Al-4Nb-4V-0.3Mo- $\mathrm{Y}$ alloy and from the center of the forging cake of Ti-45Al-5.4V-3.6Nb-Y. A vacuum tube-type heat treatment furnace was used to study the formation of lamellar structure for current $\beta$-solidifying TiAl alloys. Water quenching was adopted to investigate the high-temperature phase composition of Ti-44Al-4Nb-4V-0.3Mo-Y alloy. The specimens were heat treated at different temperature for $2 \mathrm{~h}$ and then water quenched (WQ) or furnace cooled (FC).

The microstructural characterization was performed by Quanta 200 FEG and Tescan MRIA3 field-emission scanning electron microscopy (SEM) using backscattered electrons mode (BSE). The chemical composition of local area was detected by SEM equipped with an energy dispersive X-Ray spectroscopy (EDS). Five images per condition were analyzed to obtain the mean value. Microstructural specimens were mechanical grounded and electro-polished. Electro-polishing was implemented at $-19 \mathrm{~V}$ and $-45{ }^{\circ} \mathrm{C}$ and the electrolyte was a solution of $6 \%$ perchloric acid $+34 \%$ butanol $+60 \%$ methanol. 


\section{Results and Discussion}

\subsection{Ti-45Al-5.4V-3.6Nb-Y Alloy}

It is a common consensus that the lamellar structure is the result of the transformation $\alpha \rightarrow \alpha_{2} \rightarrow \mathrm{L}$ $\left(\alpha_{2} / \gamma\right)$ in both conventional solidification and $\beta$-solidifying TiAl alloys ( $\mathrm{L}$ indicates lamellae), regardless of their processing conditions [14,15]. The microstructure of as-forged Ti-45Al-5.4V-3.6Nb-Y alloy is shown in Figure 1. As a typical $\beta$-solidifying TiAl alloy, after hot forging in $(\alpha+\gamma+\beta)$ three-phase field at $1250{ }^{\circ} \mathrm{C}$, its microstructure consisted of $\gamma$-phase, $\beta / \beta_{0}$-phase, and lamellar structure. The microstructure with streamline can be clearly seen in Figure $1 \mathrm{a}$, which is perpendicular to the deformation orientation. The orientation of lamellar structure was rotated to vertical with the deformation axis and $\beta / \beta_{0}$-phases were elongated along the streamline. Furthermore, some of the elongated $\beta / \beta_{0}$-phases were broken into small particles. It is noticeable that there was no single $\alpha_{2}$-phase in this as-forged structure. This can be mainly attributed to the transformation into lamellar structure $\left(\alpha_{2} / \gamma\right)$ from $\alpha$-phase during the subsequent cooling process. EDS analysis of the local area as marked in Figure $1 \mathrm{~b}$ is summarized in Table 1 . As can be seen, Ti element and $\beta$-phase stabilizing elements $\mathrm{V}$ and $\mathrm{Nb}$ mainly segregated in $\beta / \beta_{0}$-phase and $\alpha_{2}$-phase, while Al element was enriched in $\gamma$-phase. As revealed in the literature [17], the segregation of $\beta$-phase stabilizing elements in $\beta / \beta_{0}$-phase is more serious than $\alpha / \alpha_{2}$-phase. So positions $A, B$ and $C$ in Figure $1 b$ can be clarified as the single $\gamma$-phase, single $\beta / \beta_{0}$-phase and $\left(\alpha_{2}+\gamma\right)$ lamellar structure, respectively.

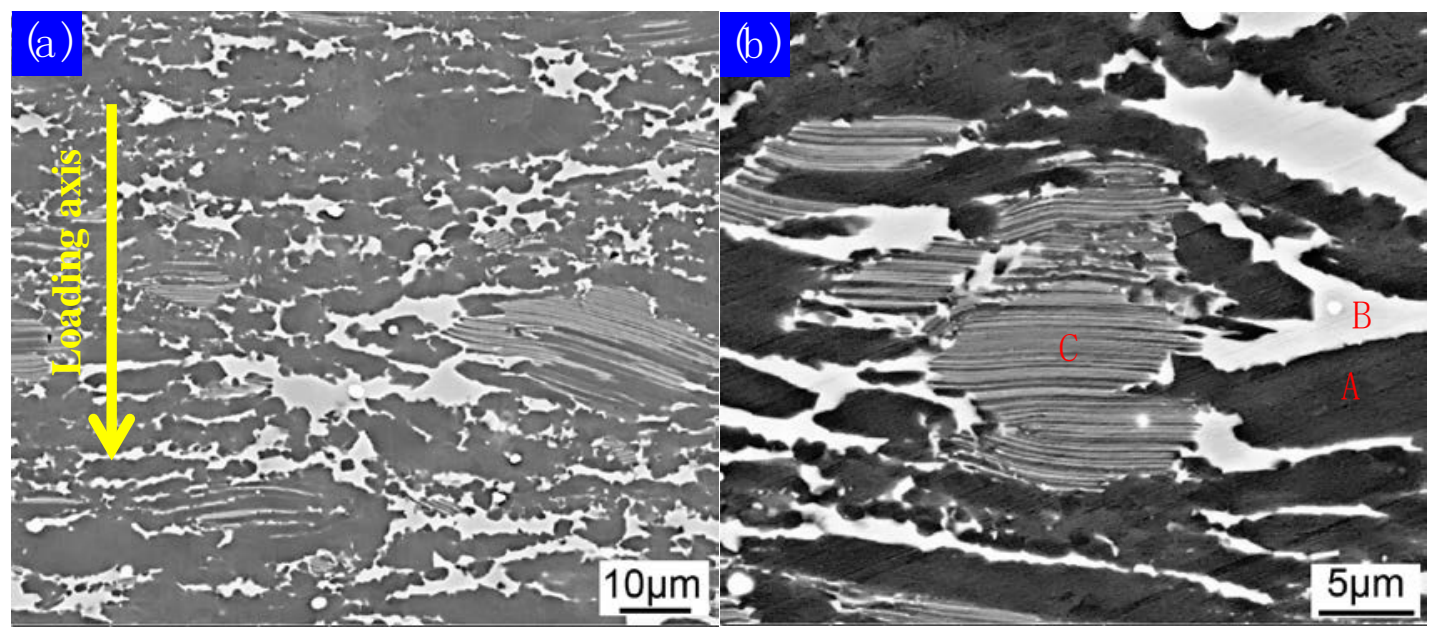

Figure 1. The microstructure of as-forged Ti-45Al-5.4V-3.6Nb-Y alloy in backscattered electrons (BSE) mode: (a) low magnification; (b) high magnification.

Table 1. EDS analysis of Figure 1.

\begin{tabular}{cccccc}
\hline Position & Ti (at.\%) & Al (at.\%) & V (at.\%) & Nb (at.\%) & Y (at.\%) \\
\hline A & $42 \pm 0.63$ & $50 \pm 0.75$ & $4 \pm 0.12$ & $4 \pm 0.15$ & 00.00 \\
B & $46 \pm 0.78$ & $39 \pm 0.36$ & $10 \pm 0.23$ & $4 \pm 0.33$ & 00.00 \\
C & $45 \pm 0.55$ & $46 \pm 0.69$ & $5 \pm 0.18$ & $4 \pm 0.26$ & 00.00 \\
\hline
\end{tabular}

The as-forged specimen was annealed at $1230{ }^{\circ} \mathrm{C}$ for $2 \mathrm{~h}$ with $\mathrm{FC}$ and the annealed microstructure is shown in Figure 2. The microstructure exhibited the typical near-gamma feature, mainly consisting of equiaxed $\gamma$-phase and $\beta / \beta_{0}$-phase. As illustrated in Figure $2 b$, there was a small amount of $\alpha_{2}$-phase which always distributed around $\beta / \beta_{0}$-phase ( $\alpha_{2}$-phase is marked by small red arrows). It was revealed that the annealed structure at $1230{ }^{\circ} \mathrm{C}$ was composed of $\gamma^{-}, \alpha_{2^{-}}$, and $\beta / \beta_{0}$-phase, without lamellar structure. This means that $\alpha$-phase transformed into its ordered state of $\alpha_{2}$-phase rather than the lamellar structure, even though the cooling rate was slow. With the rise of anneal temperature, the furnace cooled 
microstructure changed dramatically. As shown in Figure 2c,d, after annealing at $1260{ }^{\circ} \mathrm{C}$, the single $\alpha_{2}$-phase is instead of $\left(\alpha_{2}+\gamma\right)$ lamellar structure. When anneal temperature increased to $1300{ }^{\circ} \mathrm{C}$, the microstructure transformed to the duplex structure (illustrated in Figure 2e,f. However, it should be noted that the duplex structure at $1300{ }^{\circ} \mathrm{C}$ still contained $\beta / \beta_{0}$-phase, which mainly distributed on the interface of lamellar colony and $\gamma$ grain $\left(\beta / \beta_{0}\right.$-phase is marked by blue arrows in Figure $\left.2 f\right)$ ). When anneal temperature increased from $1230{ }^{\circ} \mathrm{C}$ to $1300{ }^{\circ} \mathrm{C}$, the fraction of $\beta / \beta_{0}$-phase deceased and $\alpha$-phase fraction ( $\alpha$ phase decomposed into lamellar structure at $1260^{\circ} \mathrm{C}$ and $1300{ }^{\circ} \mathrm{C}$ ) increased.
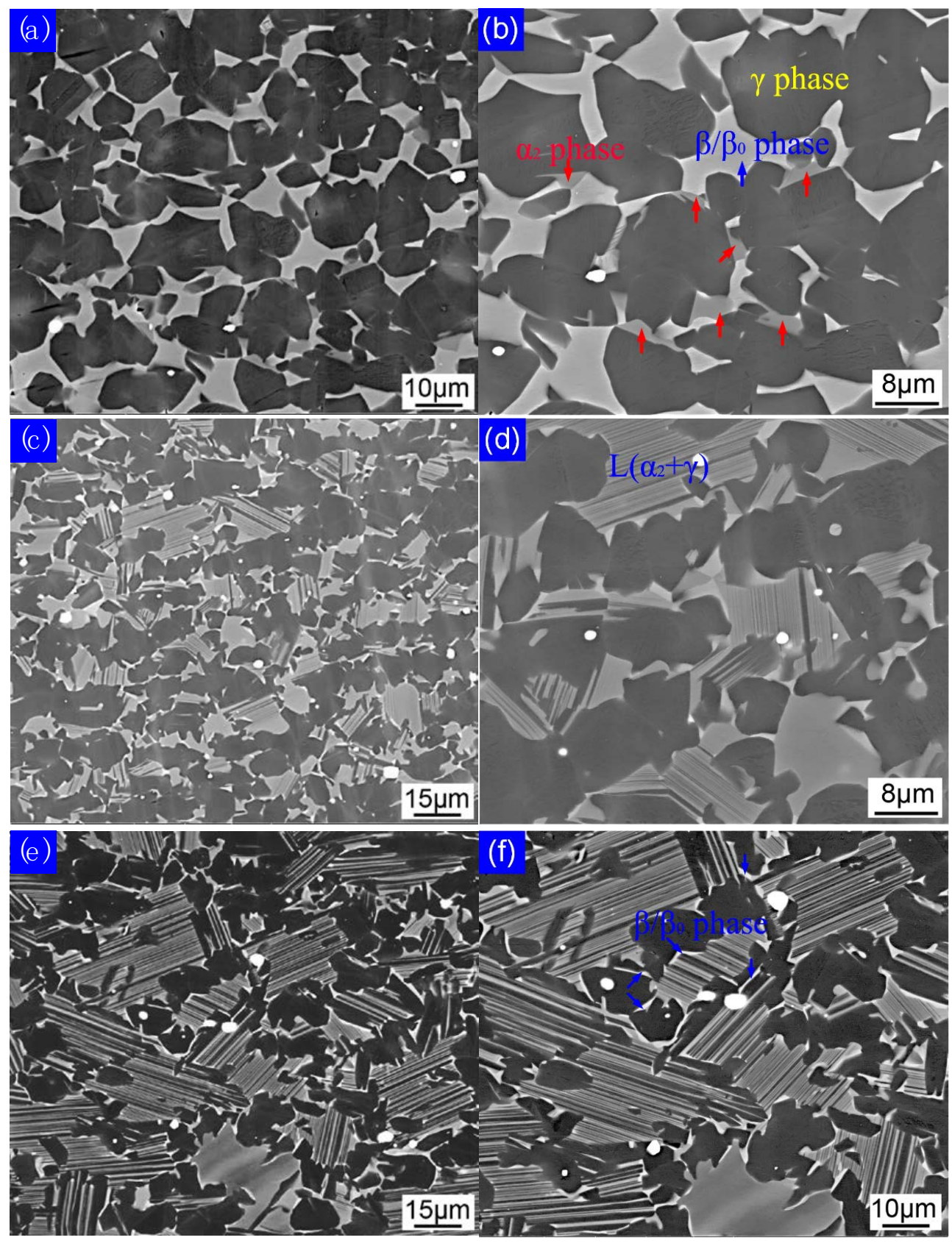

Figure 2. The microstructure of as-forged Ti-45Al-5.4V-3.6Nb-Y alloy after heat treatment at: (a,b) $1230{ }^{\circ} \mathrm{C}$; (c,d) $1260{ }^{\circ} \mathrm{C} ;(\mathbf{e}, \mathbf{f}) 1300^{\circ} \mathrm{C}$.

As reported, $\alpha$-phase could decompose into lamellar structure during slow cooling process [18]. However, as shown in Figure 2a,b, the microstructure of the as-forged alloy annealed at $1230{ }^{\circ} \mathrm{C}$, followed by furnace cooling consisting of $\alpha_{2}$-phase, $\beta / \beta_{0}$-phase, and $\gamma$-phase, without lamellar 
structure. As a disorder to order transition, the energy needed for the $\alpha \rightarrow \alpha_{2}$ phase transformation was smaller than that of the $\alpha_{2} \rightarrow \alpha_{2}+\gamma$ precipitation transition. Therefore, in view of the energy analysis, heat treatment at $1230{ }^{\circ} \mathrm{C}$ did not meet the energy requirements of $\alpha_{2} \rightarrow \alpha_{2}+\gamma$. In addition, the diffusion and solution of alloying elements were additional influence factors. First, at $1230{ }^{\circ} \mathrm{C}$, the solubility of Al element in $\alpha$-phase is lower, which did not satisfy the concentration for the precipitation of $\gamma$-phase during cooling. Furthermore, with the low temperature, the diffusion coefficient appeared to be smaller. Then the heat treatment temperature at $1230{ }^{\circ} \mathrm{C}$ was too low to improve the diffusion of $\mathrm{Al}$ element. In total, the lower energy, lower solution of $\mathrm{Al}$ in $\alpha$-phase, and smaller diffusivity of $\mathrm{Al}$ are the main reasons that $\alpha$-phase ordered into $\alpha_{2}$-phase rather than transforming into lamellar structure at $1230{ }^{\circ} \mathrm{C}$. When temperature was elevated to $1260^{\circ} \mathrm{C}$ or even higher, the higher diffusivity of $\mathrm{Al}$ promoted the nucleation and growth of $\gamma$-phase. Meanwhile, the higher temperature may have contributed to the supersaturation of $\alpha$-phase, then facilitated the precipitation of $\gamma$-phase in $\alpha_{2}$-phase reasonably. So the microstructure component of $1260{ }^{\circ} \mathrm{C}$ and $1300{ }^{\circ} \mathrm{C}$ contained a significant amount of lamellar structure and the volume fraction of lamellar structure increased with the temperature elevation.

\section{2. $\mathrm{Ti}-44 \mathrm{Al}-4 \mathrm{Nb}-4 \mathrm{~V}-0.3 \mathrm{Mo}-Y$ Alloy}

The as-cast microstructure of Ti-44Al-4Nb-4V-0.3Mo-Y alloy is shown in Figure 3, which consisted of lamellar structure, $\beta / \beta_{0}+\gamma$ block structure, and $\beta / \beta_{0}+\gamma$ pearlite-like structure. The as-cast microstructure of Ti-44Al-4Nb-4V-0.3Mo-Y alloy with less lamellar structure and more mixture structure of $\beta / \beta_{0}$-phase and $\gamma$-phase has been analyzed in previous research [14]. Due to the high content of $\beta$-stabilizer element, $\gamma$-phase discontinuously precipitated from $\beta$-phase, forming the mixture structure of $\beta$-phase and $\gamma$-phase. The microstructure of Ti-44Al-4Nb-4V-0.3Mo-Y alloy after annealing at $950{ }^{\circ} \mathrm{C}$ for $48 \mathrm{~h}$ is shown in Figure $3 \mathrm{c}, \mathrm{d}$. It is obvious that the as-annealed microstructure was mainly composed of $\gamma$-phase and $\beta / \beta_{0}$-phase.
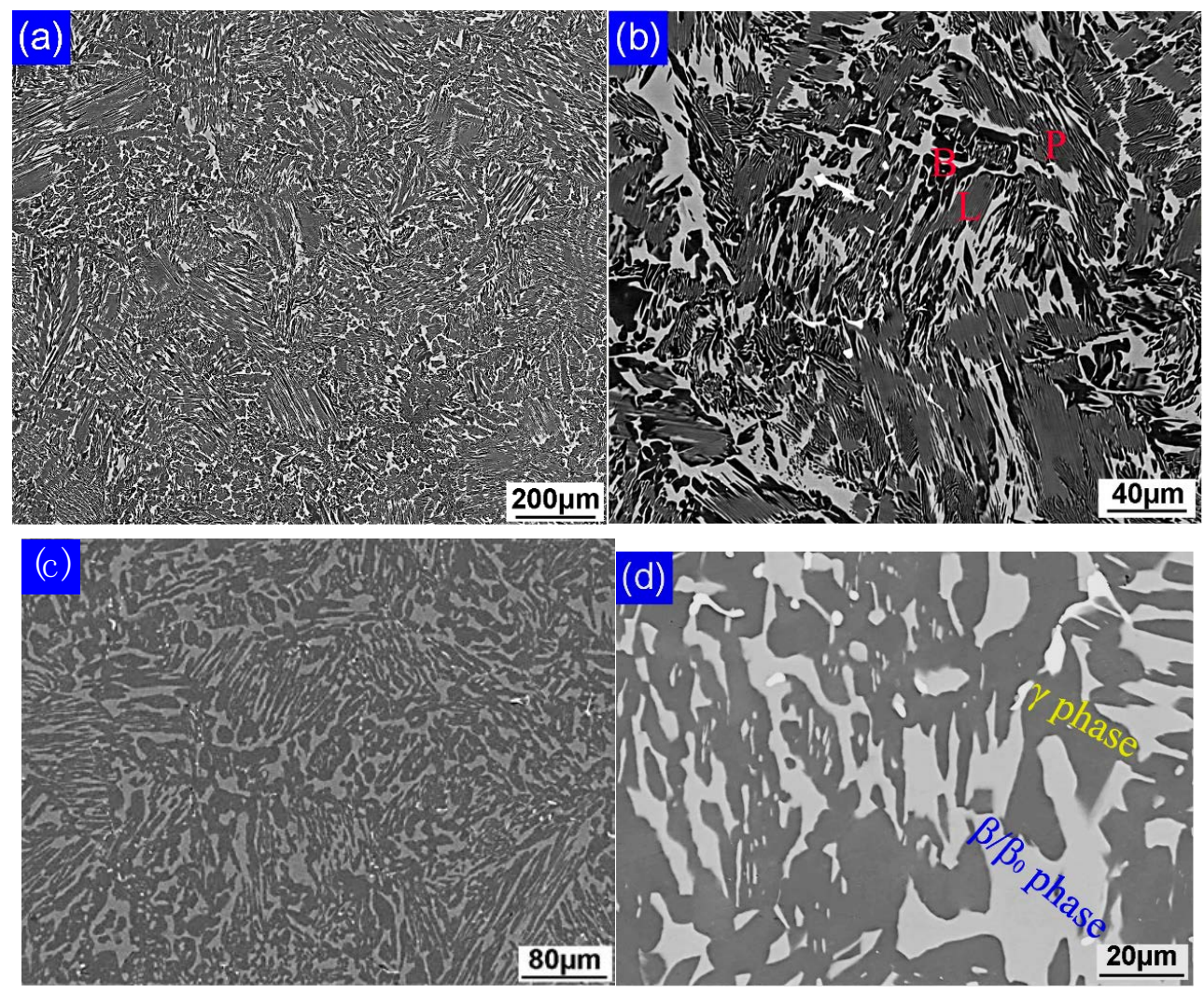

Figure 3. The microstructure of Ti- $44 \mathrm{Al}-4 \mathrm{Nb}-4 \mathrm{~V}-0.3 \mathrm{Mo}-\mathrm{Y}$ alloy: $(\mathbf{a}, \mathbf{b})$ are the as-cast condition; $(\mathbf{c}, \mathbf{d})$ are the microstructure after annealing at $950{ }^{\circ} \mathrm{C}$ for $48 \mathrm{~h}$. 
According to the Ti-Al binary phase diagram [19], this Ti-44Al-4Nb-4V-0.3Mo-Y alloy solidified through the solidification path of $\mathrm{L} \rightarrow \mathrm{L}+\beta \rightarrow \beta \rightarrow \beta+\alpha \rightarrow \beta+\alpha+\gamma \rightarrow \beta+\gamma+\alpha_{2} / \gamma$, without the single $\alpha$-phase field. As shown in Figure 4, after heat treatment at $1210{ }^{\circ} \mathrm{C}$, the volume fraction of lamellar structure was $67 \%$, while the volume fraction of lamellar structure decreased to $26 \%$ with temperature elevation to $1240{ }^{\circ} \mathrm{C}$ (the phase volume fraction was analyzed by Image J software, and 20 images per condition were used to obtain the mean value). The clear difference after heat treating at $1260{ }^{\circ} \mathrm{C}$ was that the volume fraction of lamellar structure increased to $87 \%$. This indicated that the lamellar structure fraction of this beta-gamma TiAl alloy decreased as the temperature increased from $1210^{\circ} \mathrm{C}$ to $1240{ }^{\circ} \mathrm{C}$ at first and then increased dramatically from $1240{ }^{\circ} \mathrm{C}$ to $1260{ }^{\circ} \mathrm{C}$. This tendency differed from the $\beta$-solidifying TiAl alloy, whose lamellar structure fraction monotonically increased with elevated temperatures (as discussed in the prior section).
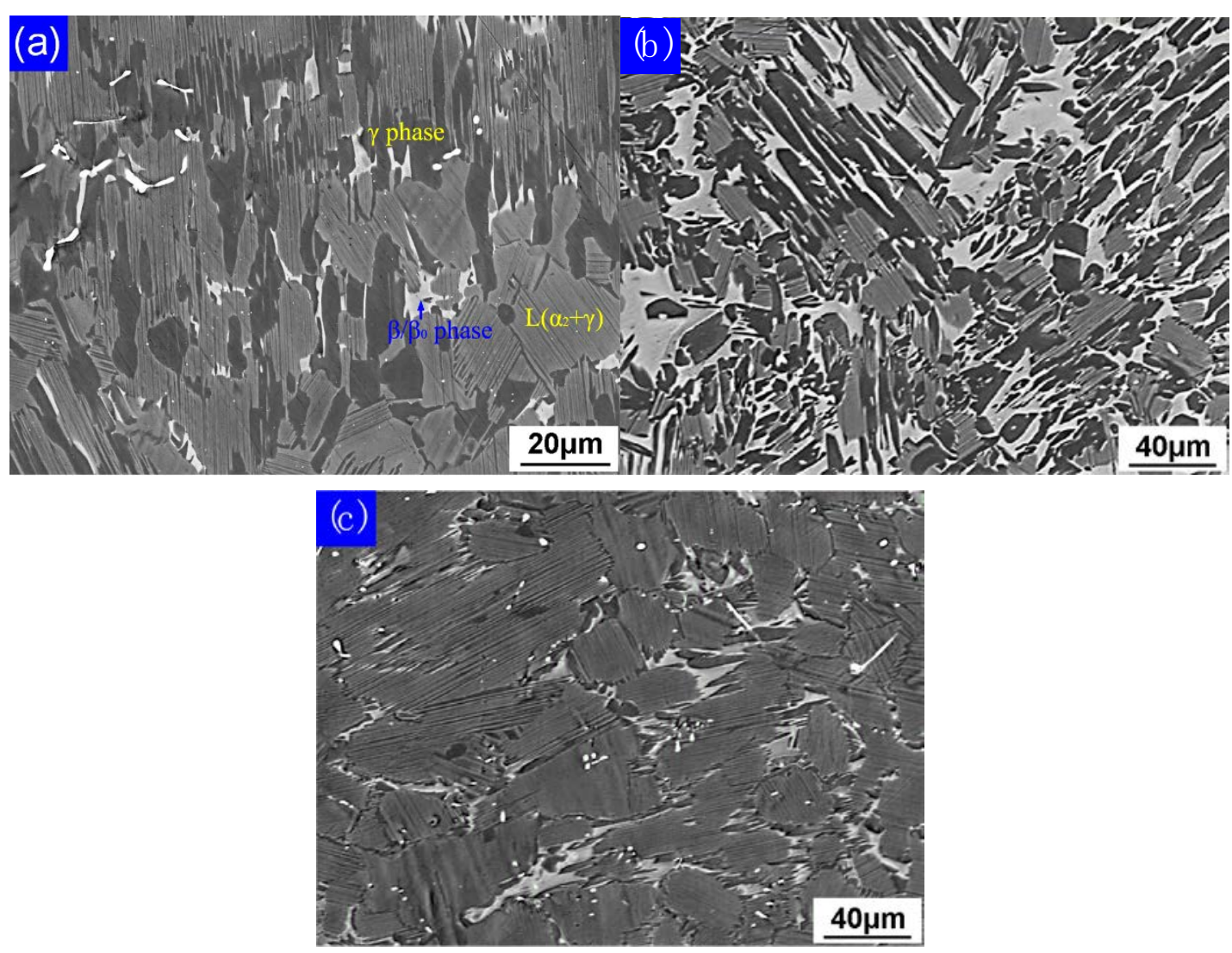

Figure 4. The microstructure of Ti-44Al-4Nb-4V-0.3Mo-Y alloy after heat treatment at: (a) $1210{ }^{\circ} \mathrm{C}$, (b) $1240{ }^{\circ} \mathrm{C}$, (c) $1260{ }^{\circ} \mathrm{C}$ for about $2 \mathrm{~h}$ and then furnace cooled.

Due to the high content of $\beta$-stabilizing elements, such as $\mathrm{Nb}, \mathrm{Mo}$, and $\mathrm{V}$, which are high melting point elements with high diffusion activation energy, the formation of lamellar structure in beta-gamma TiAl alloy was always influenced by $\beta$-stabilizing elements [20]. The slow diffusion of $\beta$-stabilizing elements and the difference of element distribution in $\beta-, \alpha-$, and $\gamma$-phase were the main influence factors. The microstructure after heat treatment and water cooling is shown in Figure 5 and the volume fraction of $\gamma$-phase, $\alpha$-phase, and $\beta$-phase is shown in Figure 6 . When quenched from $1210{ }^{\circ} \mathrm{C}$, which is located in the lower temperature region of $\alpha+\beta+\gamma$ triple phase field (as shown in Figure 7 [21]), the mean volume fraction of $\gamma$-phase, $\alpha$-phase, and $\beta$-phase were 27.8\%, 30.26\%, and $41.2 \%$, respectively. At this temperature, the transformation of $\alpha_{2}+\gamma \rightarrow \alpha$ was the main phase transition. However, the transformed $\alpha$-phase contained less $\beta$-stabilizing elements due to the high 
barrier of diffusing from $\beta$-phase to $\alpha$ phase at $1210{ }^{\circ} \mathrm{C}$. Then the $\alpha \rightarrow \alpha_{2}+\gamma$ transformation proceeded during cooling from $1210^{\circ} \mathrm{C}$, according to the solidification path.
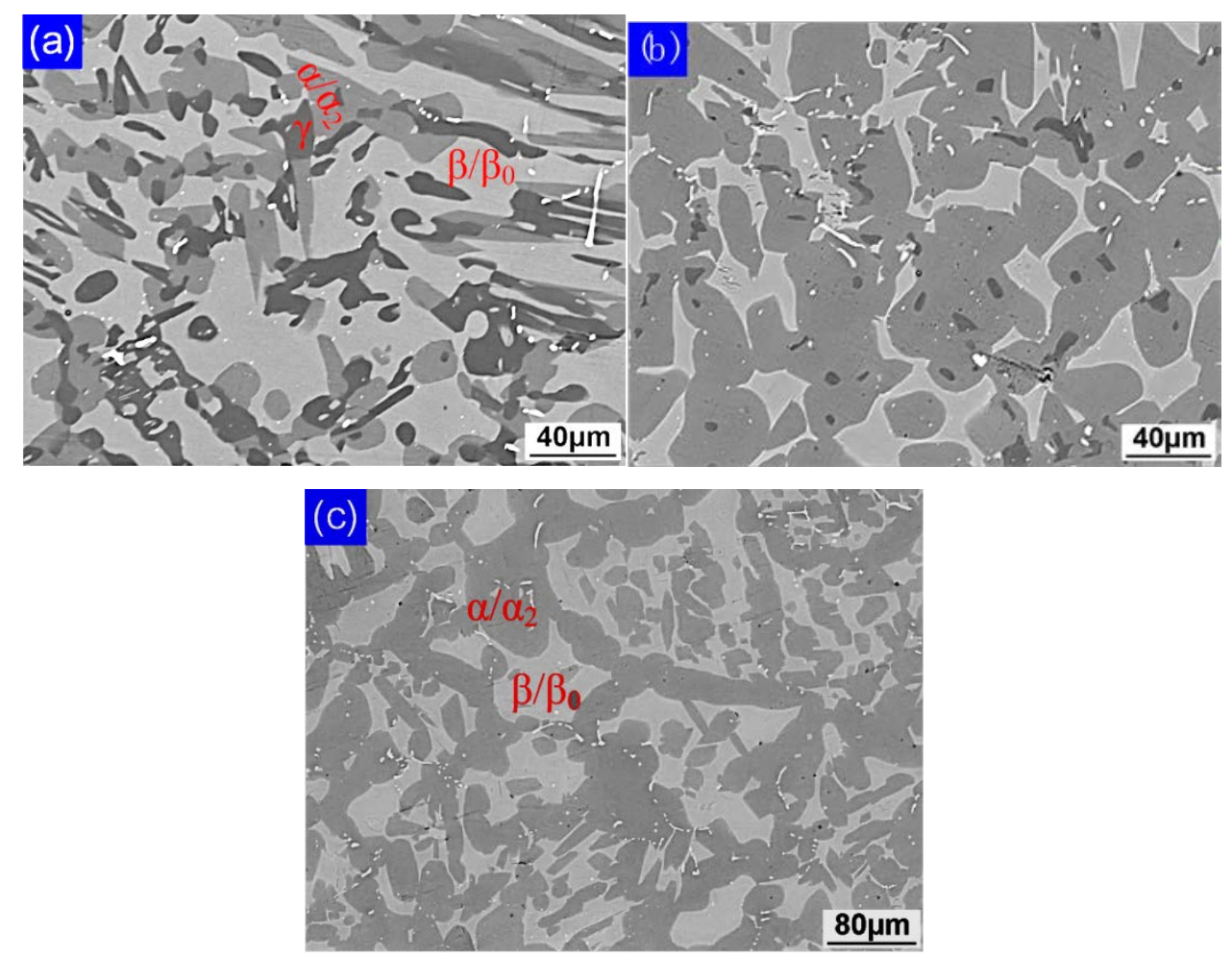

Figure 5. The microstructure of Ti- $44 \mathrm{Al}-4 \mathrm{Nb}-4 \mathrm{~V}-0.3 \mathrm{Mo}-\mathrm{Y}$ alloy after heat treatment at different temperature following water quenching: (a) $1210^{\circ} \mathrm{C}$; (b) $1240{ }^{\circ} \mathrm{C}$; (c) $1260^{\circ} \mathrm{C}$.

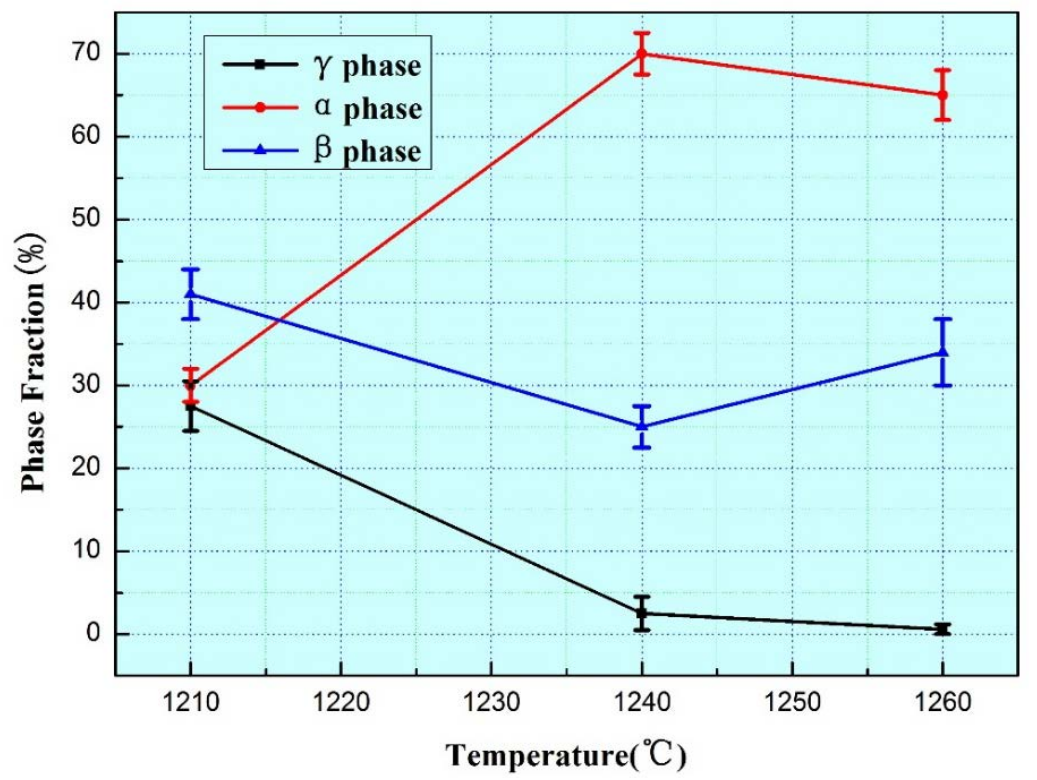

Figure 6. Volume fraction of $\gamma$-phase, $\alpha$-phase, and $\beta$-phase at different temperatures. 


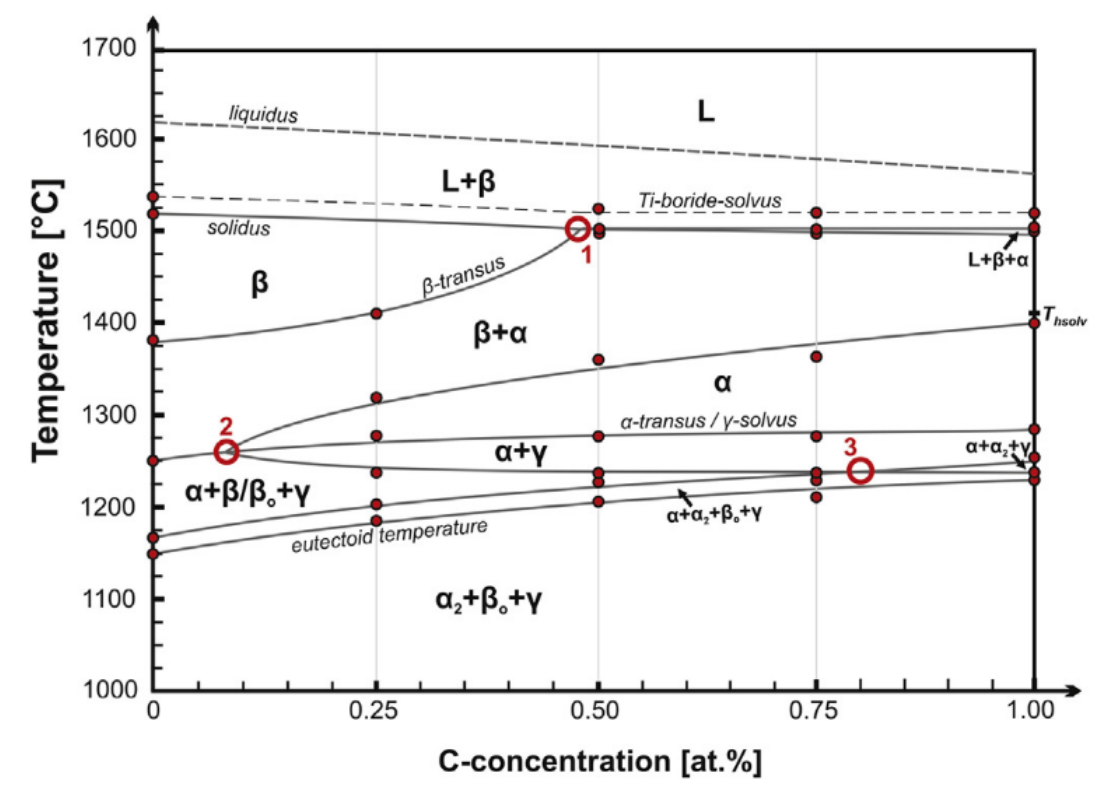

Figure 7. Phase diagram for $\beta$-solidifying TiAl alloy (Ti-43.5Al-4Nb-1Mo-0.1B-(0-1)C), reproduced from [20], with permission of Elsevier.

When temperature was elevated to $1240{ }^{\circ} \mathrm{C}$, which was still located in the $\alpha+\beta+\gamma$ triple phase field (as shown in Figure 7), the mean volume fraction of $\alpha$-phase increased to $69.7 \%$ and the mean volume fraction of $\gamma$-phase and $\beta$-phase decreased to $2.5 \%$ and $24.7 \%$, respectively. When temperature increased to $1240{ }^{\circ} \mathrm{C}$, apart from the transformation of $\alpha_{2}+\gamma \rightarrow \alpha$, the formation of $\alpha$-phase on the $\beta / \gamma$-phase interface via the transition of $\beta+\gamma \rightarrow \alpha$ appeared to be the major procedure. This phase transformation was strongly affected by the diffusibility of $\beta$-stabilizing elements. The high diffusion activation energy of these elements gave rise to the composition inhomogeneity of $\alpha$-phase transformed through the reaction of $\beta+\gamma \rightarrow \alpha$. In other words, the part of $\alpha$-phase close to $\beta$-phase contained more $\beta$-phase stabilizing elements, while more $\mathrm{Al}$ segregated in the opposite side of $\alpha$-phase, which is adjacent to $\gamma$-phase. Such inhomogeneity of the $\beta$-phase stabilizing element and $\mathrm{Al}$ in $\alpha$-phase resulted in the formation of $\beta / \beta_{0}+\gamma$ structure again, rather than lamellar structure, during the subsequent cooling process. This phenomenon appeared to be similar to the "wetting" of grain boundary by the second solid phase [22-24]. In Ti-Fe polycrystals, the $\alpha$ (Ti, Fe)-phase formed either continuous or discontinuous layers in the $\beta(\mathrm{Ti}, \mathrm{Fe}) / \beta(\mathrm{Ti}, \mathrm{Fe})$ grain boundaries (GBs), corresponding to complete or incomplete (or partial) GB wetting [21]. With the increasing anneal temperature, the thickness of continuous GB layer of $\alpha(\mathrm{Ti}, \mathrm{Fe})$-phase increased monotonously. So too does the portion of completely wetted $\beta(\mathrm{Ti}, \mathrm{Fe}) / \beta(\mathrm{Ti}, \mathrm{Fe}) \mathrm{GBs}$. According to the literature, the increase of GB layer thickness is mainly attributed to the increasing bulk diffusion coefficient of iron in titanium, corresponding to the present work. Meanwhile, the transformation temperature of $\alpha \rightarrow \beta+\gamma$ was higher than that of the transition of $\alpha \rightarrow \alpha_{2}+\gamma$. Then, with the temperature cooling down from $1240{ }^{\circ} \mathrm{C}$ to room temperature, the transformation of $\alpha \rightarrow \beta+\gamma$ was prior to the transition of $\alpha \rightarrow \alpha_{2}+\gamma$. This resulted in a phenomenon in which a certain amount of $\alpha$-phase, which was formed through $\gamma \rightarrow \alpha$ transition, would decompose into $\beta / \beta_{0}+\gamma$. This is why the volume fraction of the lamellar structure at $1240{ }^{\circ} \mathrm{C}$ was lower than that of $1210^{\circ} \mathrm{C}$ (shown in Figure 4).

With temperature increasing to $1260{ }^{\circ} \mathrm{C}(\alpha+\beta$ two phase field), as shown in Figures $5 \mathrm{c}$ and 6 , $\gamma$-phase was almost consumed. The mean volume fraction of $\alpha$-phase decreased to $65.5 \%$, while the $\beta$-phase volume fraction increased to $33.9 \%$. Then, $\alpha$-phase decomposed into $\left(\alpha_{2}+\gamma\right)$ lamellar structure during the cooling process and most of the $\beta$-stabilization elements were ejected to the interface of lamellar colonies and $\beta$-phase. Afterward, the $\beta$-phase transformed to $\beta+\gamma$ structure with temperature cooling down to $\alpha+\gamma+\beta$ triple-phase field. In a word, it was critical that temperature 
should be elevated into $\alpha+\beta$ binary-phase field or even higher to form the $\left(\alpha_{2}+\gamma\right)$ lamellar structure. Due to the influence of $\beta$-stabilizing elements, heat treatment in $\alpha+\gamma+\beta$ triple-phase field for obtaining lamellar structure was hard to accomplish. This corresponds to the literature [16] published by Niu, who reported that the full lamellar structure of beta-gamma TiAl alloy without single $\alpha$-phase can be gained through heat treatment in single $\beta$-phase field.

\section{Conclusions}

In this study, the formation of lamellar structure in as-forged Ti-45Al-5.4V-3.6Nb-Y and as-cast Ti- $44 \mathrm{Al}-4 \mathrm{Nb}-4 \mathrm{~V}-0.3 \mathrm{Mo}-\mathrm{Y}$ alloy was investigated. From the obtained results, the following conclusions could be drawn:

1. As a typical $\beta$-solidifying TiAl alloy, the as-forged microstructure of Ti-45Al-5.4V-3.6Nb-Y alloy is composed of $\gamma$-phase, $\beta / \beta_{0}$-phase, and lamellar structure. The lamellar structure formation is influenced monotonically by temperature, when heat treated at different temperatures with the same holding time. At $1230{ }^{\circ} \mathrm{C}$, the annealed structure consists of $\alpha_{2}$-phase, $\beta / \beta_{0}$-phase, and $\gamma$ phase, without lamellar structure. When the anneal temperature is elevated to $1260{ }^{\circ} \mathrm{C}$, lamellar structure becomes one of components of the furnace cooled microstructure, instead of the single $\alpha_{2}$-phase. When the temperature is increased to $1300{ }^{\circ} \mathrm{C}$, the microstructure changes to duplex structure, with more lamellar structure visible. The amount of lamellar structure increases with the increase of anneal temperature from $1260{ }^{\circ} \mathrm{C}$ to $1300^{\circ} \mathrm{C}$.

2. Ti-44Al-4Nb-4V-0.3Mo-Y alloy has no $\alpha$ single-phase field in its solidification path. Different to the Ti-45Al-5.4V-3.6Nb-Y alloy, the formation of lamellar structure of Ti-44Al-4Nb-4V-0.3Mo-Y alloy is not only affected by the heat treatment temperature but also affected by $\beta$-phase stabilizing elements. When heat treatment temperature is elevated from $1210{ }^{\circ} \mathrm{C}$ to $1240{ }^{\circ} \mathrm{C}$, the lamellar structure fraction decreases dramatically. However, a totally different tendency can be observed when temperature increases from $1240{ }^{\circ} \mathrm{C}$ to $1260^{\circ} \mathrm{C}$, which is that the volume fraction of lamellar structure clearly increases. Therefore, the heat treatment temperature, the segregation, and diffusivity of $\beta$-phase stabilizing elements are the main factors on the lamellar structure formation of Ti-44Al-4Nb-4V-0.3Mo-Y alloy.

Author Contributions: Investigation, S.Z., F.K., Y.C.; Date and Resources, S.Z., F.Y., J.H.; Data Curation and Result analysis, F.Y., J.H., C.Z.; Writing-Original Draft Preparation, J.H., S.Z.; Writing-Review \& Editing, J.H., S.Z., F.Y.; Visualization, J.H., C.Z.

Acknowledgments: This work was financially supported by the National Natural Science Foundation of China (Nos. 51604191, 51504163), the National Science Foundation of Shanxi (No. 201701D221075), and the State Key Laboratory for Advanced Metal and Materials foundation (Nos. 2014-ZD06). We also thank the financial support of the Special/Youth Foundation of Taiyuan University of Technology (Nos. 2015QN014, 2013T004 and 2013T003), the Qualified Personnel Foundation of Taiyuan University of Technology (Nos. tyutrc201342a and tyut-rc201343a), and the Taiyuan city science and technology major projects (170203).

Conflicts of Interest: The authors declare no conflict of interest.

\section{References}

1. Song, L.; Lin, J.; Li, J. Phase transformation mechanisms in a quenched Ti-45Al-8.5Nb-0.2W-0.2B-0.02Y alloy after subsequent annealing at $800{ }^{\circ} \mathrm{C}$. J. Alloys Compd. 2017, 691, 60-66. [CrossRef]

2. Wang, X.; Yang, J.; Song, L.; Kou, H.; Li, J.; Fu, H. Evolution of B2(w) region in high-Nb containing TiAl alloy in intermediate temperature range. Intermetallics 2017, 82, 32-39. [CrossRef]

3. Zhang, S.Z.; Song, Z.W.; Han, J.C.; Zhang, C.J.; Lin, P.; Zhu, D.D.; Kong, F.T.; Chen, Y.Y. Effect of 2-6 at.\% Mo addition on microstructural evolution of Ti-44Al alloy. J. Mater. Sci. Technol. 2018, 34, 1196-1204. [CrossRef]

4. Zhang, S.Z.; Zhang, C.J.; Du, Z.X.; Hou, Z.P.; Lin, P.; Kong, F.T.; Chen, Y.Y. Deformation behavior of high Nb containing TiAl based alloy in $\alpha+\gamma$ two phase field region. Mater. Des. 2016, 90, 225-229. [CrossRef] 
5. Zhou, H.T.; Kong, F.T.; Wang, X.P.; Chen, Y.Y. Hot deformation behavior and microstructural evolution of as-forged Ti-44Al-8Nb-(W, B, Y) alloy with nearly lamellar microstructure. Intermetallics 2017, 81, 62-72. [CrossRef]

6. Han, J.C.; Dong, J.; Zhang, S.Z.; Zhang, C.J.; Xiao, S.L.; Chen, Y.Y. Microstructure evolution and tensile properties of conventional cast TiAl-based alloy with trace Ni addition. Mater. Sci. Eng. A 2018, 715, 41-48. [CrossRef]

7. Erdely, P.; Staron, P.; Maawad, E.; Schell, N.; Klose, J.; Mayer, S.; Clemens, H. Effect of hot rolling and primary annealing on the microstructure and texture of a $\beta$-stabilised $\gamma$-TiAl based alloy. Acta Mater. 2017, 126, 145-153. [CrossRef]

8. Klein, T.; Rashkova, B.; Holec, D.; Clemens, H.; Mayer, S. Silicon distribution and silicide precipitation during annealing in an advanced multi-phase $\gamma$-TiAl based alloy. Acta Mater. 2016, 110, 236-245. [CrossRef]

9. Janschek, P. Wrought TiAl Blades. Mater. Today Proc. 2015, 2, S92-S97. [CrossRef]

10. Liu, H.; Li, Z.; Gao, F.; Liu, Y.; Wang, Q. High tensile ductility and strength in the Ti-42Al-6V-1Cr alloy. J. Alloys Compd. 2017, 698, 898-905. [CrossRef]

11. Shen, Z.Z.; Lin, J.P.; Liang, Y.F.; Zhang, L.Q.; Shang, S.L.; Liu, Z.K. A novel hot pack rolling of high $\mathrm{Nb}-\mathrm{TiAl}$ sheet from cast ingot. Intermetallics 2015, 67, 19-25. [CrossRef]

12. Cao, G.; Fu, L.; Lin, J.; Zhang, Y.; Chen, C. The relationships of microstructure and properties of a fully lamellar TiAl alloy. Intermetallics 2000, 8, 647-653. [CrossRef]

13. Wang, J.N.; Xie, K. Grain size refinement of a TiAl alloy by rapid heat treatment. Scr. Mater. 2000, 43, 441-446. [CrossRef]

14. Jones, S.A.; Kaufman, M.J. Phase equilibria and transformations in intermediate titanium-aluminum alloys. Acta Metall. Mater. 1993, 41, 387-398. [CrossRef]

15. Inui, H.; Oh, M.H.; Nakamura, A.A.; Yamaguchi, A.M. Ordered domains in TiAl coexisting with $\mathrm{Ti}_{3} \mathrm{Al}$ in the lamellar structure of Ti-rich TiAl compounds. Philos. Mag. A 1992, 66, 539-555. [CrossRef]

16. Niu, H.Z.; Chen, Y.Y.; Zhang, Y.S.; Lu, J.W.; Zhang, W.; Zhang, P.X. Producing fully-lamellar microstructure for wrought beta-gamma TiAl alloys without single $\alpha$-phase field. Intermetallics 2015, 59, 87-94. [CrossRef]

17. Kainuma, R.; Fujita, Y.; Mitsui, H.; Ohnuma, I.; Ishida, K. Phase equilibria among $\alpha$ (hcp), $\beta$ (bcc) and $\gamma\left(\mathrm{L1}_{0}\right)$ phase in Ti-Al base ternary alloys. Intermetallics 2000, 8, 855-867. [CrossRef]

18. Hu, D.; Botten, R.R. Phase transformations in some TiAl-based alloys. Intermetallics 2002, 10, $701-715$. [CrossRef]

19. Schuster, J.C.; Palm, M. Reassessment of the binary aluminum-titanium phase diagram. J. Phase Equilib. Diff. 2006, 27, 255-277. [CrossRef]

20. Han, J.; Xiao, S.; Tian, J.; Chen, Y.; Xu, L.; Wang, X.; Jia, Y.; Du, Z.; Cao, S. Grain refinement by trace TiB 2 addition in conventional cast TiAl-based alloy. Mater. Charact. 2015, 106, 112-122. [CrossRef]

21. Schwaighofer, E.; Rashkova, B.; Clemens, H.; Stark, A.; Mayer, S. Effect of carbon addition on solidification behavior, phase evolution and creep properties of an intermetallic beta-stabilized gamma-TiAl based alloy. Intermetallics 2014, 46, 173-184. [CrossRef]

22. Gornakova, A.S.; Straumal, B.B.; Nekrasov, A.N.; Kilmametov, A.; Afonikova, N.S. Grain Boundary Wetting by a Second Solid Phase in Ti-Fe Alloys. J. Mater. Eng. Perform. 2018, 1-4. [CrossRef]

23. Straumal, B.B.; Kilmametov, A.R.; Ivanisenko, Yu.; Gornakova, A.S.; Mazilkin, A.A.; Kriegel, M.J.; Fabrichnaya, O.B.; Baretzky, B.; Hahn, H. Phase Transformations in Ti-Fe Alloys Induced by High-Pressure Torsion. Adv. Eng. Mater. 2016, 17, 1835-1841. [CrossRef]

24. Lo'pez, G.A.; Mittemeijer, E.J.; Straumal, B.B. Grain Boundary Wetting by a Solid Phase; Microstructural Development in a Zn-5 wt\% Al Alloy. Acta Mater. 2004, 52, 4537-4545. [CrossRef]

(C) 2018 by the authors. Licensee MDPI, Basel, Switzerland. This article is an open access article distributed under the terms and conditions of the Creative Commons Attribution (CC BY) license (http:/ / creativecommons.org/licenses/by/4.0/). 